\title{
Establishing a Molecular Genetic Diagnosis in Children with Differences of Sex Development: A Clinical Approach
}

\author{
Michele A. O'Connell ${ }^{a, b, c}$ Gabby Atlas ${ }^{a, b, c}$ Katie Ayers ${ }^{b, c}$ Andrew Sinclair ${ }^{b, c}$ \\ aDepartment of Endocrinology and Diabetes, The Royal Children's Hospital Melbourne, Melbourne, VIC, Australia; \\ ${ }^{\mathrm{b}}$ Reproductive Development, Murdoch Children's Research Institute, Melbourne, VIC, Australia; 'Department of \\ Paediatrics, University of Melbourne, Melbourne, VIC, Australia
}

\section{Keywords}

Children and adolescents - Differences of sex development .

Genetics · Genitalia · Sexual development

\begin{abstract}
Background: Despite distinct underlying aetiologies, the clinical phenotypes and hormonal profiles of children with various differences of sex development (DSD) are often similar, which presents challenges to ascertaining an accurate diagnosis on clinical grounds alone. Associated features and important clinical outcomes can, however, vary significantly in different DSD, thus establishing an accurate molecular diagnosis may have important implications for decision-making and management planning in a given individual. Summary: The wider availability of next-generation sequencing techniques in recent years has led to recommendations for earlier integration of genetic testing in the diagnostic pathway of children with DSD. This review provides a practical overview of the clinical applications, advantages, and limitations of the more commonly available diagnostic genetic tests and outlines a suggested approach to testing. The potential clinical implications of a confirmed genetic diagnosis, subsequent management pathways for individuals with
\end{abstract}

DSD, and challenges that remain to be addressed are also outlined. Key Messages: Despite significant improvements in our understanding of the complex genetic pathways that underlie DSD, an accurate diagnosis still eludes many affected individuals. Establishing a molecular diagnosis provides aetiological certainty, enabling improved information for families and individualized clinical management, including monitoring or prophylactic intervention where additional health risks exist. A stepwise approach to genomic testing is recommended to afford highest diagnostic yield from available resources. Looking forward, collaborative multicentre prospective studies will be required to assess the true impact of a genetic diagnosis on improving clinical care pathways and health, well-being and patient-reported outcomes for individuals with DSD.

(c) 2021 S. Karger AG, Basel

\section{Introduction}

The umbrella term differences of sex development "DSD" - refers to a heterogeneous group of congenital conditions that arise when chromosomal, gonadal or anatomical sex is atypical [1]. Terminology in this area is 
controversial, and while DSD is currently the most broadly used and accepted medical term (hence adopted hereafter), many affected individuals prefer terms such as intersex, variations in sex characteristics $[2,3]$, or where possible, precise terminology relating to their own condition [4]. Although many individual variations are rare, DSD overall are not uncommon. Prevalence estimations vary depending on the definitions applied, but range from infrequent variations such as 46 , XX testicular DSD (3.8 per 100,00 newborn males [5]) to significant variations in genital appearance such that sex cannot be determined from phenotype alone ( 1 in 4,500 live births) and hypospadias affecting up to 1 in 125 boys [6-9].

Broadly speaking, DSD may arise due to differences in (i) sex chromosomal complement (sex chromosome aneuploidy, e.g., Turner syndrome [45,X or mosaicism] or Klinefelter syndrome [47,XXY or mosaicism]); (ii) genes or genomic regulators involved in gonadal development (giving rise to complete, partial or mixed gonadal dysgenesis or other gonadal variations such as ovotesticular DSD); (iii) steroid hormone biosynthesis (e.g., 21-hydroxylase deficiency congenital adrenal hyperplasia [21OHD CAH] or 5-alpha reductase 2 deficiency [5ARD2]); (iv) sex hormone responsiveness (e.g., complete or partial androgen insensitivity syndrome [CAIS/ PAIS]); or (v) hypothalamic-pituitary-gonadal axis signalling. Additionally, environmental influences such as maternal or placental factors or endocrine disruptors in pregnancy and increasingly, altered gene expression due to epigenetic changes in pregnancy, are recognized aetiologies. At a genomic level, multiple aetiologies have been elucidated, ranging from whole-chromosome aneuploidies to copy number variants (CNVs) affecting open reading frames or regulatory regions upstream of critical genes (e.g., SOX9, SOX3, or NROB1 [10]) to single-nucleotide variants (SNVs) in $>70$ genes involved in sex development [11-14]. The molecular mechanisms involved in DSD have been comprehensively reviewed elsewhere [9, $14,15]$ and a detailed overview is beyond the scope of this article. Major single genes known to be associated with DSD and their more commonly described variant types are outlined in Table 1.

Clinically, DSD encompass a broad spectrum of often similar phenotypes and hormonal profiles, hence delineating the underlying aetiology in a given child is clinically challenging. It is however recognized that associated features, clinical, and well-being outcomes may markedly differ among various DSD, meaning that further investigation to establish a precise diagnosis is important [1618]. Most common DSD presentations include atypical genital appearance relative to binary male or female "norms" at birth, virilization or detection of inguinal testes in a phenotypically female infant or young child, and absence of pubertal development or unexpected virilization in an adolescent girl. Increasingly, non-invasive prenatal testing examining cell-free fetal DNA heralds the need for further investigation of either antenatally detected sex chromosomal aneuploidies that may result in a DSD, or a discordant genital phenotype (female) relative to the antenatal karyotype $(46, \mathrm{XY})$ in a newborn infant [19-21].

DSD are initially classified according to sex chromosome complement, with further sub-classification relating to more specific pathophysiology [1]. Gonadal development is often affected by the various aneuploidies that comprise sex chromosome DSD; however, external genital appearance is usually not atypical. In contrast, children with 46,XY DSD commonly present with degrees of atypical external genital virilization at birth $[22,23]$. Individuals with 46,XX DSD frequently exhibit signs of increased in utero androgen exposure, with resultant "virilization" of external genital phenotype. This most commonly arises due to $21 \mathrm{OHD} \mathrm{CAH}$, while rarer causes include other adrenal enzyme pathway disruptions or the presence of testicular tissue (e.g., 46,XX testicular DSD or $46, \mathrm{XX}$ ovotesticular DSD) $[24,25]$.

In the three decades since the initial discovery of the sex-determining gene SRY [26-28], significant research effort and technological advances have led to important advances in unravelling the complex network of genes that regulate gonadal and genital development $[9,12,15$, $29,30]$, yet our understanding of the genomic basis of DSD nonetheless remains incomplete. While use of nextgeneration sequencing (NGS) techniques has resulted in higher rates of identification of causative or likely causative variants, an accurate diagnosis remains elusive for many individuals with DSD $[30,31]$, including up to $2 / 3$ of those with 46,XY karyotype [30, 32].

Phenotypic overlap across different aetiologies as well as variability arising from discrete variants in an individual gene compound the clinical diagnostic challenge. This may reflect the intricate genetic interplay in the regulation of sex development as well as the multiple, temporalspecific roles of a given gene within this pathway. NR5A1 is a good illustration of a gene with important roles in multiple stages of sex development, including an early role in development of the bi-potential gonad, subsequent upregulation of SOX9 early in testis development, as well as upregulation of anti-Mullerian hormone in the Sertoli cells, and of steroidogenic enzymes involved in sex 
Table 1. Genes and variant types associated with DSD

\begin{tabular}{|c|c|c|c|}
\hline Gene name & Types of variant & DSD subtype & $\begin{array}{l}\text { Level of } \\
\text { evidence }\end{array}$ \\
\hline \multicolumn{4}{|c|}{ Disorders of gonadal development } \\
\hline BMP15 & SNV & $46, \mathrm{XX}$ gonadal dysgenesis & Medium \\
\hline CBX2 & SNV & $46, X X$ and $46, X Y$ gonadal dysgenesis & Medium \\
\hline $\mathrm{DHH}$ & SNV & $46, X Y$ gonadal dysgenesis \pm minifasicular neuropathy & High \\
\hline DHX37 & SNV & $46, \mathrm{XY}$ gonadal dysgenesis & High \\
\hline DMRT1 & Gene deletion & $46, X Y$ gonadal dysgenesis & Low \\
\hline DMRT2 & Gene deletion & $46, X Y$ gonadal dysgenesis & Low \\
\hline ESR2 & SNV & $46, X Y$ gonadal dysgenesis & Low \\
\hline FGFR2 & Deletion & $46, \mathrm{XY}$ gonadal dysgenesis & Medium \\
\hline GATA4 & SNV and deletions & $46, X Y$ DSD \pm congenital heart defect & Medium \\
\hline MAMLD1 & Deletion & Isolated hypospadias & Medium \\
\hline MAP3K1 & SNV & $46, X Y$ gonadal dysgenesis & High \\
\hline NROB1 & Duplications, inversion, and upstream deletion & $46, X Y$ gonadal dysgenesis & High \\
\hline NR5A1 & SNV, partial gene deletion, and deletion & $\begin{array}{l}46, X Y \text { gonadal dysgenesis } \\
46, X X \text { ovotesticular DSD }\end{array}$ & High \\
\hline RSPO1 & SNV and deletion & $46, X X$ ovotesticular DSD & Medium \\
\hline SOX10 & Duplication & $46, \mathrm{XX}$ ovotesticular and testicular DSD & Medium \\
\hline SOX3 & Upstream deletion and duplication & $46, \mathrm{XX}$ ovotesticular and testicular DSD & Medium \\
\hline SOX8 & SNV, upstream duplication, and inversion & $46, X Y$ gonadal dysgenesis & Medium \\
\hline SOX9 & SNV, upstream deletion, and duplication & $\begin{array}{l}46, X Y \text { gonadal dysgenesis } \\
46, X X \text { ovotesticular and testicular DSD }\end{array}$ & High \\
\hline$S R Y$ & SNV, deletion, and translocation & $46, \mathrm{XY}$ gonadal dysgenesis $46, \mathrm{XX}$ testicular/ovotesticular DSD & High \\
\hline WNT4 & SNV and duplication & $\begin{array}{l}46, X X \text { ovotesticular and testicular DSD } \\
46, X Y \text { DSD }\end{array}$ & Medium \\
\hline ZFPM2 & SNV and balanced translocation & $\begin{array}{l}46, X Y \text { gonadal dysgenesis } \\
46, X X \text { ovotesticular DSD }\end{array}$ & Medium \\
\hline ZNRF3 & SNV & $46, X Y$ gonadal dysgenesis & Medium \\
\hline \multicolumn{4}{|c|}{ Steroid hormone biosynthesis defects } \\
\hline$A K R 1 C 2$ & SNV & Backdoor steroidogenesis deficiency & Medium \\
\hline$A K R 1 C 4$ & SNV & Backdoor steroidogenesis deficiency & Low \\
\hline CYB5A & SNV & Cytochrome b5 deficiency & Medium \\
\hline CYP11A1 & SNV, deletion and duplication & $\mathrm{CAH}$ & High \\
\hline CYP11B1 & SNV & $\mathrm{CAH}$ & High \\
\hline CYP17A1 & SNV & $\mathrm{CAH}$ & High \\
\hline CYP19A1 & SNV & Aromatase deficiency & High \\
\hline CYP21A2 & SNV, deletion & $\mathrm{CAH}$ & High \\
\hline HSD17B3 & SNV & 17-beta hydroxysteroid dehydrogenase 3 deficiency & High \\
\hline HSD3B2 & SNV & $\mathrm{CAH}$ & High \\
\hline LHCGR & SNV & $46, X Y$ DSD with Leydig cell hypoplasia & High \\
\hline NR3C1 & SNV & Glucocorticoid insensitivity & High \\
\hline POR & SNV & P450-oxidoreductase deficiency & High \\
\hline SRD5A2 & SNV & 5-alpha reductase deficiency & High \\
\hline STAR & SNV & StAR deficiency (lipoid CAH) & High \\
\hline \multicolumn{4}{|c|}{ Sex hormone responsiveness } \\
\hline$A R$ & SNV and deletion & CAIS or PAIS & High \\
\hline \multicolumn{4}{|c|}{$46, X Y$ DSD with atypical AMH responsiveness } \\
\hline$A M H$ & SNV & Persistent Mullerian duct syndrome & Medium \\
\hline AMHR2 & SNV & Persistent Mullerian duct syndrome & Medium \\
\hline \multicolumn{4}{|c|}{ Hypothalamic-pituitary-gonadal axis signalling } \\
\hline ANOS1 (KAL1) & SNV & Hypogonadotrophic hypogonadism & High \\
\hline DUSP6 & SNV & Hypogonadotrophic hypogonadism & High \\
\hline FEZF1 & SNV & Hypogonadotrophic hypogonadism & Medium \\
\hline FGF17 & SNV & Hypogonadotrophic hypogonadism & Medium \\
\hline
\end{tabular}

Establishing a Genetic Diagnosis in Children with DSD
Horm Res Paediat

DOI: 10.1159/000520926 
Table 1 (continued)

\begin{tabular}{|c|c|c|c|}
\hline Gene name & Types of variant & DSD subtype & $\begin{array}{l}\text { Level of } \\
\text { evidence }\end{array}$ \\
\hline FGF8 & SNV & Hypogonadotrophic hypogonadism & High \\
\hline FGFR1 & SNV & Hypogonadotrophic hypogonadism & High \\
\hline FSHB & SNV & Hypogonadotrophic hypogonadism & High \\
\hline FSHR & SNV & $46, \mathrm{XX}$ ovarian dysgenesis & High \\
\hline GNRH1 & SNV & Hypogonadotrophic hypogonadism & Medium \\
\hline GNRHR & SNV & Hypogonadotrophic hypogonadism & High \\
\hline HESX1 & SNV & Hypogonadotrophic hypogonadism & High \\
\hline IL17RD & SNV & Hypogonadotrophic hypogonadism & Medium \\
\hline INSL3 & SNV & Cryptorchidism & Medium \\
\hline KISS1 & SNV & Hypogonadotrophic hypogonadism & Low \\
\hline KISS1R & SNV & Hypogonadotrophic hypogonadism & High \\
\hline$L H B$ & SNV & Hypogonadotrophic hypogonadism & High \\
\hline$L H X 3$ & SNV & Hypogonadotrophic hypogonadism & High \\
\hline PROK2 & SNV & Hypogonadotrophic hypogonadism & High \\
\hline PROKR2 & SNV & Hypogonadotrophic hypogonadism & High \\
\hline PROP1 & SNV & Multiple pituitary hormone deficiency & High \\
\hline RXFP2 & SNV & Cryptorchidism & Low \\
\hline TAC3 & SNV & Hypogonadotrophic hypogonadism & Medium \\
\hline TACR3 & SNV & Hypogonadotrophic hypogonadism & High \\
\hline WDR11 & SNV & Hypogonadotrophic hypogonadism & High \\
\hline \multicolumn{4}{|c|}{ Syndromic DSD } \\
\hline$A R X$ & SNV & Lissencephaly, epilepsy with partial gonadal dysgenesis & Medium \\
\hline ATRX & SNV & $\begin{array}{l}\text { X-linked thalassaemia with intellectual disability and } \\
\text { hypogonadism }\end{array}$ & High \\
\hline CDKN1C & SNV & $\begin{array}{l}\text { IMAGe syndrome with genital abnormalities, adrenal } \\
\text { dysplasia, and metaphyseal dysplasia }\end{array}$ & High \\
\hline CHD7 & SNV & CHARGE syndrome, genital abnormalities & High \\
\hline DHCR7 & SNV & Smith-Lemli-Opitz syndrome with genital abnormalities & High \\
\hline $\mathrm{DHH}$ & SNV & $46, X Y$ gonadal dysgenesis \pm minifasicular neuropathy & High \\
\hline EMX2 & SNV & $\begin{array}{l}\text { Partial gonadal dysgenesis with intellectual disability and } \\
\text { kidney agenesis }\end{array}$ & Low \\
\hline FOXL2 & SNV & BPES with premature ovarian failure & Medium \\
\hline GATA4 & SNV and deletion & $46, X Y$ DSD \pm congenital heart defect & Medium \\
\hline HHAT & SNV & Nivelon-Nivelon-Mabille syndrome with gonadal dysgenesis & Low \\
\hline HOXA13 & SNV & $\begin{array}{l}\text { Hand-foot-genital syndrome with hypospadias or Mullerian } \\
\text { fusion }\end{array}$ & Medium \\
\hline HSD17B4 & SNV & Perrault syndrome with 46,XX ovarian dysgenesis & Medium \\
\hline MYRF & SNV & Cardiac-urogenital syndrome & High \\
\hline POR & SNV & P450-oxidoreductase deficiency and Antley-Bixler syndrome & High \\
\hline PPP1R12A & SNV & $\begin{array}{l}\text { Genitourinary and/or brain malformation syndrome, with } \\
46, X Y \text { genital abnormalities }\end{array}$ & High \\
\hline SAMD9 & SNV & MIRAGE syndrome with genital abnormalities & High \\
\hline SOX9 & SNV, upstream deletion and duplication & Gonadal dysgenesis and campomelic dysplasia & High \\
\hline TSPYL1 & SNV & $46, X Y$ DSD with sudden infant death syndrome & Medium \\
\hline WT1 & SNV and gene deletion & $\begin{array}{l}\text { Gonadal dysgenesis, as part of Denys-Drash or Frasier } \\
\text { syndromes }\end{array}$ & High \\
\hline
\end{tabular}

Levels of evidence: high = multiple publications ( $>5$ variants) of affected individuals/families \pm functional genomics confirmation; medium $=$ small published number of cases ( 5 or less variants), across $>1$ family; low = published evidence relates to one affected family only. $\mathrm{AMH}$, anti-Mullerian hormone; BPES, blepharophimosis-ptosis-epicanthus inversus syndrome; $\mathrm{CAH}$, congenital adrenal hyperplasia; CAIS, complete androgen insensitivity syndrome; CHARGE syndrome, coloboma, heart defects, atresia choanae, growth retardation, genital abnormalities, ear abnormalities; DSD, differences of sex development; IMAGe syndrome, intrauterine growth restriction, metaphyseal dysplasia, adrenal hypoplasia, and genitourinary abnormalities; MIRAGE syndrome, myelodysplasia, infection, restriction of growth, adrenal hypoplasia, genital phenotypes, and enteropathy; PAIS, partial androgen insensitivity syndrome; SNV, single-nucleotide variant. 
differentiation and maintenance of both male and female pathways [33-36]. As a result, the exceptionally wide phenotypic spectrum of NR5A1 variants is well documented. In 46,XY individuals, NR5A1-related mutations and $\mathrm{CNV}$ may give rise to complete gonadal dysgenesis [37], undervirilization and male infertility $[33,34]$, while in $46, \mathrm{XX}$ DSD, primary ovarian insufficiency [38] and $46, \mathrm{XX}$ ovotesticular and testicular DSD [7, 39, 40] are among the more commonly recognized phenotypes. In addition, identical pathogenic NR5A 1 variants may result in completely different phenotypes, illustrating varying degrees of expressivity and incomplete penetrance associated with this gene and highlighting the possibility of digenic [41] and oligogenic [42] causes, whereby the combination of an additional "second-hit" variant in related genes influences the phenotypic presentation of a given individual.

\section{Diagnostic Approach - Limitations of Clinical Evaluation and Biochemical Testing to Establish a DSD Diagnosis}

Management at a tertiary centre by a multidisciplinary team with appropriate expertise is standard of care $[1,16$, 43] and requires an integrated clinical, biochemical, and molecular genetics approach. A detailed history and physical examination are important for all children with suspected DSD. Maternal history during pregnancy (virilization or medications such as progestogens) and family history to assess for other affected family members and/or suggested patterns of inheritance may direct diagnostic suspicion. Examination of newborns/infants should include general physical assessment in addition to more targeted genital examination. For older children, the latter requires significant sensitivity and should only be undertaken when specifically relevant (e.g. where the child or family raise concern regarding atypical appearance or a change in genital appearance). In this scenario, its purpose should be explained to the child and consent/ assent should be obtained. The presence of dysmorphic features, other extra-genital clinical features, or learning difficulties may indicate a syndromic cause for a DSD [44]. A detailed overview of all syndromic associations is beyond the scope of this article, but recommended assessment includes anthropometry, facies, cardiac, limb, and digit examinations [45]. Small for gestational age is reported in up to $25 \%$ of individuals with DSD [46] with cardiac and neurological features found in 20\% [46]. Salient phenotypic features that may be evident in asso- ciation with atypical genital development in a neonate include bony abnormalities (e.g., campomelic dysplasia, Antley-Bixler syndrome), midline clefts (e.g., Opitz syndrome and Smith-Lemli-Opitz syndrome), ophthalmological signs (e.g., aniridia [WAGR/11p deletion syndrome], coloboma [CHARGE syndrome] or blepharophimosis, epicanthus inversus, and ptosis), facial dysmorphism (e.g., Smith-Lemli-Opitz syndrome, alpha thalassaemia $x$-linked intellectual disability), polydactyly and syndactyly (e.g., Smith-Lemli-Opitz), choanal variations (e.g., CHARGE syndrome, Antley-Bixler syndrome), and structural cardiac variations (CHARGE syndrome), among others.

The external masculinization score (EMS) [47] and the more recently validated gender-neutral external genital score (EGS) [48] offer standardized approaches to documenting genital appearance. Both scores incorporate assessment of the presence or absence of externally palpable gonads, phallic size, site of urethral meatus, and degree of fusion of labioscrotal folds. Further investigation is recommended for children with an EMS of $<11$ or an EGS of $<10.5$ [18]. The Prader score can also be used to document genital findings in 46,XX infants [49]. Alongside assessment of the degree of fusion (which begins posteriorly), inspection of the labioscrotal folds should assess for rugosity, hyperpigmentation (which raises suspicion for $\mathrm{CAH}$ ), and symmetry of appearance (asymmetry may indicate mixed gonadal dysgenesis or OT-DSD). Perineal examination should assess the number of orifices present. Since the time-sensitive, adequate production and action of testicular hormones are required for internal and external genital differentiation in a male pattern [50], information regarding the relative amount and timing of fetal androgen exposure can be inferred from the external genital appearance [44]. For example, in children with 46,XY DSD, a bifid or unfused scrotum alongside atypical masculine urethral formation indicates relative androgen deficiency early in pregnancy (8-14 weeks' gestation), whereas androgen deficiency later in pregnancy predominantly impacts growth of the phallus [51]. The combination of a bifid scrotum and smaller than typical phallus in a baby with 46,XY chromosomes therefore indicates androgen deficiency arising early and persisting throughout pregnancy; if testes are palpable, an androgen biosynthetic defect or androgen insensitivity may be suspected. In contrast, an enlarged phallus without labioscrotal fusion or a masculine urethra indicates predominant exposure to androgens in the second half of pregnancy, as may arise, for example, in some $46, \mathrm{XX}$ children with $\mathrm{CAH}$. 
Establishing sex chromosome complement allows DSD sub-classification [1], and in particular, the presence or absence of $\mathrm{Y}$ chromosome material guides further first-line investigations. Thereafter, biochemical or steroid hormone evaluation [52] may facilitate early diagnosis for some children with DSD. In particular, the patterns of steroid hormone precursors and androgen excess that typify $21 \mathrm{OHD} \mathrm{CAH}$ (which comprises $90-95 \%$ of $\mathrm{CAH}$, [53]) can be recognized either through newborn screening and/or on steroid hormone analysis early in the diagnostic workup. As endocrine testing profiles are diagnostic, confirmatory genetic testing is not routinely undertaken at many centres.

In contrast, for those with 46,XY DSD, traditional diagnostic pathways are commonly more protracted [54] and often unhelpful in establishing a diagnosis [55]. Nonetheless, biochemical workup is important as it can reveal underlying pathology and inform hormonal treatments [16]. Hormonal testing in such instances aims to establish the presence of functioning testicular tissue and typically comprises analysis of gonadotropin ( $\mathrm{LH}$ and FSH) levels, testosterone (T), dihydrotestosterone (DHT), anti-Mullerian hormone, and/or inhibin B levels, with additional assessment of $\mathrm{T}$ and DHT production following human chorionic gonadotropin (hCG) stimulation $[17,18,56]$. Comprehensive steroid profile analysis to identify 46,XY DSD that may be associated with acute adrenal insufficiency (e.g., StAR or P450scc deficiencies and some NR5A1 variants) is also recommended [52]. Additional testing for potential ovarian tissue (e.g., oestradiol production if sex chromosome mosaicism suggests possible ovotesticular DSD) or concomitant renal pathology (e.g., Denys-Drash or Frasier syndrome with WT1 mutations) should also be considered.

Pitfalls in these traditional pathways are well recognized. Cross-reactivity with other steroids limits the utility of immunoassay-based methods of serum androgen measurement in the newborn period [57]. Liquid chromatography-mass spectrometry improves the accuracy of serum androgen measurement but is not universally readily available [52]. Following hCG stimulation, an elevated T:DHT ratio reflecting the underlying enzymatic deficiency is classically reported in individuals with $5 \mathrm{ARD} 2$; however, low sensitivity and specificity of this increased T:DHT ratio is problematic $[58,59]$. Similar issues limit the utility of androstenedione: $\mathrm{T}$ ratios in 17 beta hydroxysteroid dehydrogenase deficiency [60]. Given the high age-dependent variation in steroid synthesis and metabolism, urinary steroid profiling with gas chromatography-mass spectrometry to identify $5 \mathrm{ARD} 2$ defi- ciency is unreliable and typically not recommended in the first 3 months of life, yet important decisions regarding sex of rearing may be needed in this timeframe. More broadly, available hormonal testing protocols and resultant profiles are poorly discriminatory, with clear overlap in profiles both among individuals with clinically similar but genetically distinct DSD subtypes [58] as well as between those who do and do not have an underlying variation [61]. Furthermore, it is important to note that apparently normal hormonal profiles do not preclude an underlying DSD; indeed, this was the case for $52 \%$ of a UK cohort of children with a genetically confirmed 46,XY DSD [55]. Although imaging may assist with identification of gonad position and internal genital structure, findings on both US and MRI may also be misleading, with variable sensitivity and specificity rates for identifying structures described [62]. The gold standard for the evaluation of internal genital structures and gonads is laparoscopy ( \pm gonadal biopsy); however, this is both invasive and expensive.

\section{Potential Benefits of Establishing a Genetic Diagnosis}

The key potential benefits of a genetic diagnosis include (1) improved understanding of the underlying aetiology of an individual's DSD which in turn will (2) inform prediction of their clinical trajectory and shared decision-making with families in relation to sex of rearing and other management decisions, (3) aid in prediction of gonadal malignancy risk, (4) allow identification or instigation of screening for extra-genital features known to be associated with a specific gene variant, and (5) assist with reproductive planning for the family. In addition, there may be both psychological and health resource benefits to confirm an underlying diagnosis and end the "diagnostic odyssey."

Together with improved understanding of the genomic basis of DSD, recent decades have seen important changes in the broader landscape of clinical management of DSD, with a greater focus on a more conservative approach to management, particularly in relation to interventions with irreversible effects $[16,23]$. Recently published pathways for clinical management recognize the benefits of establishing an early diagnosis to better inform joint decision-making between clinical teams and families to promote and improve long-term health and patient-reported outcomes [16, 18, 23, 63]. Future gonadal hormone production, hormone responsiveness, gender 
contentedness, risk of gonadal malignancy, and fertility potential are important clinical outcomes for individuals with DSD, but these outcomes may vary markedly in different variations $[16,64,65]$.

In conditions such as 5ARD2 or 17-beta hydroxysteroid dehydrogenase deficiency, where neonatal phenotype may be predominantly female, androgen production increases significantly with consequent masculinizing physical changes at puberty. While gender role change has previously been estimated to occur in approximately 1 in 2 individuals with these androgen biosynthetic defects $[64,66,67]$, this is not a consistent outcome and indeed much lower rates $(<10 \%)$ have been reported in some cohorts $[59,65]$ than documented elsewhere (39$60 \%[66,68,69])$. Factors that influence gender contentedness and gender identity are not well elucidated but may include the degree of androgen exposure (both prenatal and peri-pubertal) as well as cultural and societal considerations. Recognition and affirmation of non-binary gender identities is also important [65]. In contrast, individuals with other 46,XY DSD such as CAIS or complete or severe partial gonadal dysgenesis, who also have more typically female genital appearance at birth but lower subsequent relative androgen effect, have much higher rates of female gender identity $[65,70]$, similar to those reported in 46,XX populations without known DSD. Incorporating knowledge relating to future androgen exposure, its potential impact on identity and diagnosis-specific implications for fertility $[71,72]$ is important when considering and discussing optimal sex of rearing with the family, underscoring the value of an early genetic diagnosis $[23,43,73]$. Diagnostic confirmation of androgen biosynthetic disorders, such as $5 \mathrm{ARD} 2$, for example, can also assist with choice of androgen replacement therapy.

Factors that contribute to the higher gonadal germ cell tumour risk in $46, \mathrm{XY}$ and $45 \mathrm{X} / 46 \mathrm{XY}$ DSD include the degree of gonadal (under)development, gonadal position, and older age $[74,75]$. Highest risk is found in those with gonadal dysgenesis, particularly due to variants in genes involved in the earliest stages of gonadal development (e.g., $S R Y, W T 1$, and $D H H$ ) [76]. Improved diagnostic accuracy has contributed to revised estimations of gonadal malignancy risk for many DSD subtypes, most notably AIS, in the past 15 years [77, 78]. As gonadal malignancy risk influences decision-making regarding irreversible interventions such as gonadectomy in individuals with DSD, these revisions have had important clinical implications. Historically, many 46,XY babies born with genital ambiguity were given a clinical diagnosis of exclusion of "likely PAIS." Malignancy risk for intra-abdomi-

Establishing a Genetic Diagnosis in Children with DSD nal gonads in PAIS was previously estimated at $~ 50 \%$ [77], hence prophylactic gonadectomy to mitigate this risk was recommended [1]. More recently, data from cohorts with genetic confirmation of underlying diagnosis indicate that while the risk remains at $\sim 30 \%+$ for those with gonadal dysgenesis and intra-abdominal gonads [78], it is now estimated to be considerably lower in PAIS than previously attributed ( $7 \%$ across studies where causative androgen receptor variant was genetically confirmed) [76]. This has led to a re-appraisal of early childhood prophylactic gonadectomy in AIS and other 46XY DSD with lower malignancy risk such as altered hormone biosynthesis $(<5 \%)[75,76]$, with benefits of allowing endogenous hormone production at puberty and facilitating involvement of the individual in decision-making related to their gonads, including discussions relating to fertility, increasingly prioritized [16, 23, 78-80].

As discussed above, DSD are not uncommonly accompanied by extra-genital associations or syndromic features $[44,46]$, reflecting the involvement of many DSDrelated genes, particularly those that encode transcription factors, in broader embryonic development (see Table 1). While some features, such as campomelic dysplasia associated with structural and coding variants of SOX9 [81], would be phenotypically prominent, this is not always the case. Examples of extra-gonadal associations that may not be clinically evident but would warrant investigations upon identification of a relevant genomic variant include congenital heart disease with GATA4 variants [82], minifascicular neuropathy with $D H H$ gene variants $[83,84]$, and renal implications of various WT1 mutations [85].

\section{Genomic Testing and Its Application in DSD}

The relative advantages, disadvantages, and clinical utility of various genetic tests that may be employed in the investigation of a child with DSD are summarized in Table 2. Where possible, inclusion of a clinical geneticist in the DSD MDT to advise on optimal testing pathways in a given individual, particularly for children with additional syndromic features, is recommended $[16,18,86]$.

\section{Chromosomal Analysis}

First-line investigation for DSD should always include confirming the chromosomal sex. Typically, this involves a molecular karyotype; however, when more rapid results are required for counselling and decision-making (in the neonatal setting), additional testing with either fluorescence in situ hybridization (FISH) or quantitative fluores- 
Table 2. Utility of different genetic tests for establishing a diagnosis in DSD

\begin{tabular}{|c|c|c|c|c|c|}
\hline & Test application & $\begin{array}{l}\text { Time to } \\
\text { result }\end{array}$ & Cost & Benefits & Limitations \\
\hline \multirow[t]{2}{*}{$\mathrm{FISH}$} & $\begin{array}{l}\text { Rapid Y/SRY detection in a } \\
\text { neonate or infant }\end{array}$ & Days & $\$ \$$ & Rapid turnaround time & Labour intensive \\
\hline & & & & Can detect mosaicism & \\
\hline \multirow[t]{2}{*}{ QF-PCR } & $\begin{array}{l}\text { Rapid Y/SRY detection in a } \\
\text { neonate or infant }\end{array}$ & Hours & $\$$ & Rapid turnaround time & Limited assessment for mosaicism \\
\hline & & & & Automated process & $\begin{array}{l}\text { Typically limited to chromosomes } \\
13,18,21, X, Y\end{array}$ \\
\hline Karyotype & Determining chromosomal sex & Days & $\$$ & $\begin{array}{l}\text { Chromosome analysis, can detect mosaicism } \\
\text { and structural rearrangements }\end{array}$ & $\begin{array}{l}\text { Low resolution - can only detect large }{ }^{\#} \\
\text { chromosomal rearrangements }\end{array}$ \\
\hline \multirow[t]{3}{*}{ Microarray } & $\begin{array}{l}\text { Determining chromosomal sex } \\
\text { Identification of CNV }\end{array}$ & $\begin{array}{l}\text { Days- } \\
\text { weeks }\end{array}$ & $\$ \$$ & May detect non-coding variations & Less effective at detecting mosaicism \\
\hline & & & & Can identify small* CNV & $\begin{array}{l}\text { Does not detect triplet repeats, } \\
\text { balanced translocations, inversions, or } \\
\text { point mutations }\end{array}$ \\
\hline & & & & Useful in syndromic DSD & \\
\hline \multirow[t]{3}{*}{ Gene panel } & $\begin{array}{l}\text { Simultaneous assessment of a } \\
\text { number of known DSD genes }\end{array}$ & $\begin{array}{l}\text { Weeks- } \\
\text { months }\end{array}$ & $\$ \$$ & $\begin{array}{l}\text { Can provide better coverage of a panel of } \\
\text { genes than WES }\end{array}$ & $\begin{array}{l}\text { Not standardized across laboratories } \\
\text { (variability in genes included in panels) }\end{array}$ \\
\hline & & & & $\begin{array}{l}\text { Less chance of incidental findings compared } \\
\text { to WES }\end{array}$ & Limited number of genes tested \\
\hline & & & & Can detect SNV & $\begin{array}{l}\text { No scope to reanalyse with new/ } \\
\text { additional genes later }\end{array}$ \\
\hline \multirow[t]{4}{*}{ WES } & $\begin{array}{l}\text { Undiagnosed DSD - assessment } \\
\text { of variants in the protein-coding } \\
\text { regions of the genome }\end{array}$ & $\begin{array}{l}\text { Weeks- } \\
\text { months }\end{array}$ & $\$ \$$ & $\begin{array}{l}\text { Initial analysis can be limited to known DSD } \\
\text { genes of interest }\end{array}$ & Excludes the non-coding genome \\
\hline & & & & $\begin{array}{l}\text { Can reanalyse data as new DSD genes are } \\
\text { reported }\end{array}$ & $\begin{array}{l}\text { Does not easily detect CNV, large } \\
\text { deletions/duplications, triplet repeat } \\
\text { expansions, gross chromosome } \\
\text { changes, and methylation } \\
\text { abnormalities }\end{array}$ \\
\hline & & & & Ability to discover novel genes & Higher chance of incidental findings \\
\hline & & & & Comprehensive sequencing & $\begin{array}{l}\text { Variant interpretation is time } \\
\text { consuming }\end{array}$ \\
\hline \multirow[t]{4}{*}{ WGS } & $\begin{array}{l}\text { Undiagnosed DSD - assessment } \\
\text { of all coding and non-coding } \\
\text { DNA sequences }\end{array}$ & Months & $\$ \$ \$$ & Includes non-coding genome & Data storage \\
\hline & & & & $\begin{array}{l}\text { Can identify variants not detectable on } \\
\text { exome, e.g., mitochondrial DNA, triplet } \\
\text { repeats }\end{array}$ & High probability of VUS \\
\hline & & & & & $\begin{array}{l}\text { Limited availability and expertise in } \\
\text { interpretation of non-coding variants }\end{array}$ \\
\hline & & & & More uniform coverage & Cost \\
\hline
\end{tabular}


cence polymerase chain reaction (QF-PCR) is recommended. The FISH protocol is cumbersome and timeconsuming and has largely been replaced by QF-PCR [10], where available. QF-PCR has a rapid turnaround time (same day result may be possible) and detects a series of markers on the sex chromosomes [13]. Identification of markers for both the Y chromosome and SRY are typically utilized to assist with DSD sub-classification and further direct additional investigations. If chromosomal DSD is identified, there is often no need to proceed with further genetic analysis.

A G-band karyotype can be undertaken to confirm the full chromosome complement, any structural abnormality, and the presence of chromosome translocation or mosaicism [87]. While this is a more established method of detecting sex chromosome mosaicism [13], it has a slower turnaround time of approximately 5 days. Karyotype is also limited by low resolution and can only detect very large $(>5-10 \mathrm{Mb})$ chromosomal rearrangements. As a result, a microarray is increasingly utilized for more detailed initial chromosomal assessment.

\section{Microarray}

A number of key genes in the pathways of sex development are known to have dose-dependent effects. In 46,XY DSD, these include duplications of DAX1 or WNT4 and deletions of ATRX, DMRT1, EMX2, or WT1, while duplications of SOX3 or SOX9 are recognized causes of 46,XX DSD [13] (see Table 1). Overall, CNV are estimated to comprise $>20 \%$ of DSD $[88,89]$, although additional $\mathrm{CNV}$ in non-coding regions are proposed as a likely cause of undiagnosed DSD [10]. Traditionally, FISH was utilized to detect large-scale genomic CNV; however, the cumbersome nature of its protocol renders it unsuitable for screening large cohorts. Higher resolution chromosomal analysis with microarray affords genome-wide identification of both microdeletions and microduplications and CNV as a potential cause of DSD. In many centres, microarray has replaced G-banded karyotype for analysis of sex chromosomes; however, it is less effective at detecting mosaicism (particularly if $<10 \%$ of analysed cells) and will not detect structural chromosomal rearrangements such as translocations and inversions (unless accompanied by a CNV). A microarray is particularly useful for making a diagnosis for syndromic individuals with DSD, where CNV are more prevalent $[88,89]$ and for those with associated extra-genital features or other system involvements [90].

Different forms of microarray include array comparative genomic hybridization (aCGH) and single-nucleo-

Establishing a Genetic Diagnosis in Children with DSD tide polymorphism (SNP) arrays [91]; availability can vary between centres. aCGH is a powerful high-resolution technique that utilizes DNA of both test and control samples labelled with different fluorescent tags. Comparison of the relative fluorescent signal identifies regions of gain or loss of genetic material in the patient samples when compared directly with the control sample. Most clinically available aCGH platforms are capable of detecting aneuploidies, well-characterized microdeletions or microduplications, and subtelomeric or other unbalanced chromosomal rearrangements. CNV of potential relevance to the child's DSD (e.g., previously unreported but occurring in a region that contains candidate genes or arising de novo) that warrant further investigation may also be detected. In recent years, aCGH has contributed to recognition of novel upstream enhancers that regulate expression of the key testis gene, SOX9; when duplicated or deleted, these enhancers resulted in $46, \mathrm{XX}$ or $46, \mathrm{XY}$ DSD, respectively [92]. SNP arrays have higher resolution than aCGH and can identify homozygosity, heterozygosity, regions of loss of homozygosity, and consanguinity. This method detects changes in a copy number by measuring changes in intensity of a particular SNP bound to a fluorescent probe, indicating a duplication or deletion of a region.

Many commercially available microarray techniques only detect $\mathrm{CNV}>25-50 \mathrm{~kb}$ and hence are less effective for detecting small genetic variations. Notwithstanding this, microarray techniques are an important component of genetic testing and have identified a number of key deletions and duplications in both coding regions and regulatory regions of genes such as $S O X 9, S O X 3, N R O B 1$, and GATA4 [88, 93-95]. In the research setting, microarray may aid in identification of novel genetic variations in the non-coding regulatory regions of DSD-associated genes [96].

\section{Sanger Sequencing (Single Gene)}

Sanger sequencing utilizes fluorescently labelled chain-terminating dideoxynucleotides for DNA synthesis and can provide base pair resolution of fragments of up to 1,000 base pairs [96]. However, data from the DSDTranslational Research Network indicate that even in "targeted gene" analysis (following clinical phenotyping and biochemical testing at specialist DSD centres), it has proven poorly discriminatory, with negative results in $\sim 40 \%$ and $\sim 55 \%$ of $A R$ and SRD $5 A 2$ gene tests, respectively [29]. The increased availability of NGS techniques that facilitate simultaneous assessment of DNA base pairs across a selected groups of genes (targeted gene panels), 
the exome (whole exome sequencing) or genome (whole genome sequencing), has facilitated a move away from a sequential gene-by-gene approach to the diagnostic pathway. Given the large number of potentially causative genes and the significant overlap in phenotypic presentation of DSD, NGS has obvious diagnostic, cost, and efficiency benefits. Nonetheless, Sanger sequencing remains beneficial for segregation of a specific variant within a family, for targeted sequencing of genes where complexities (e.g., presence of a highly homologous pseudogene in CYP21A2) limit NGS interpretation, or to validate or augment NGS-derived data (e.g., insufficient read depth coverage).

\section{Targeted Gene Panels}

SNV are the most frequently reported genetic variant in individuals with 46 , XY DSD, so a gene panel is a costeffective method for directly screening multiple known diagnostic and candidate DSD genes. Through targeted NGS, simultaneous analysis of a large number of genes can be performed in a relatively short time period. This allows a panel of candidate genes with appropriate coverage of all genomic regions of interest to be analysed and since only select regions are sequenced, the rate of incidental findings (in genes not relevant to phenotype) is decreased [97]. NGS requires bioinformatics expertise, however with the reduced data set, the load can be less challenging. DSD gene panels are not currently standardized, and there are a number of different panels utilized worldwide, with reported diagnostic yields ranging 20 $45 \%$ [14, 30, 96, 98-101]. Although such panels have proven very beneficial, limitations are also recognized. Modification of an original gene panel is expensive, so undiagnosed patients need to be retested (at additional cost) as novel genes are discovered. Using a predefined DSD gene panel also limits the ability to discover new candidate genes. As discussed below, where available, many laboratories are moving towards "virtual" DSD gene panels built and analysed on an exome backbone.

\section{Whole-Exome Sequencing}

The increased availability of whole-exome sequencing (WES) has transformed the clinical genetic diagnosis capabilities for undiagnosed rare disorders including DSD. WES provides the sequencing information of all known protein-coding regions of the genome, which can then be analysed simultaneously for variant identification. Exome sequencing captures and sequences all exons and the immediately adjacent splice sites, covering about 45 million base pairs. A gene list (or "virtual panel") is analysed us- ing a WES backbone for relevant DSD genes. With decreasing costs and improvements in bioinformatics in recent years, WES is a more widely available clinical tool. A significant advantage of WES is its greater flexibility relative to panel-based approaches - since all exons are sequenced, genomic data of individuals without a diagnosis can be reanalysed as new DSD-gene associations are reported [29, 102]. Moreover, WES allows for additional genes or simultaneous virtual panels to be curated and analysed, depending on the clinical phenotype. Broadly speaking, the diagnostic yield of WES for monogenic disorders is increased when analysed as a trio with both phenotyped parents being sequenced along with the proband $[86,103,104]$, as identification of inherited and de novo variants decreases the number of variants that need curation. Notwithstanding that however, given the additional costs involved, reflexing to trio testing if singleton testing does not yield a diagnosis may be a more cost-effective approach [104].

WES has facilitated discovery of likely pathogenic variants in a number of genes not previously recognized to have DSD associations (e.g., SOX8 [105], ZNRF3 [106], DHX37 [107], and RXFP2 [108]) and novel variants with new phenotypic associations in known DSD genes (e.g., NR5A1 in 46,XX DSD [35]) [13,96] and allowed further expansion of the molecular basis for various syndromic DSD [109]. In addition, the more detailed bioinformatics analyses that WES affords have led to recognition of potential oligogenic causes of DSD $[42,110]$ as well as novel candidate genes [111] which may be more frequently identified with increasing use of WES in DSD cohorts moving forward.

WES brings the challenges of variants of unknown significance (VUS) in genes that may or may not have previously been associated with DSD and the ethical issues associated with incidental findings. Until recently, costs and slower turnaround times have precluded widespread utilization of WES as a first-line diagnostic investigation in many clinical settings. Technical advances have meant that incomplete gene coverage is less frequently problematic, although it may still be lower than that of targeted gene panels. "Per base pair" costs are also reducing; however, interpretation of variants remains highly labour intensive. While robust analysis pipelines [112] and multidisciplinary involvement are likely to enhance the accuracy and reliability of variant interpretation, the cumulative cost of these resources needs to be considered and may not be feasible in limited resource settings. Since exons comprise only $1-2 \%$ of the genome, many variants outside of these coding regions will be missed with WES.
10

Horm Res Paediat DOI: $10.1159 / 000520926$
O'Connell/Atlas/Ayers/Sinclair 


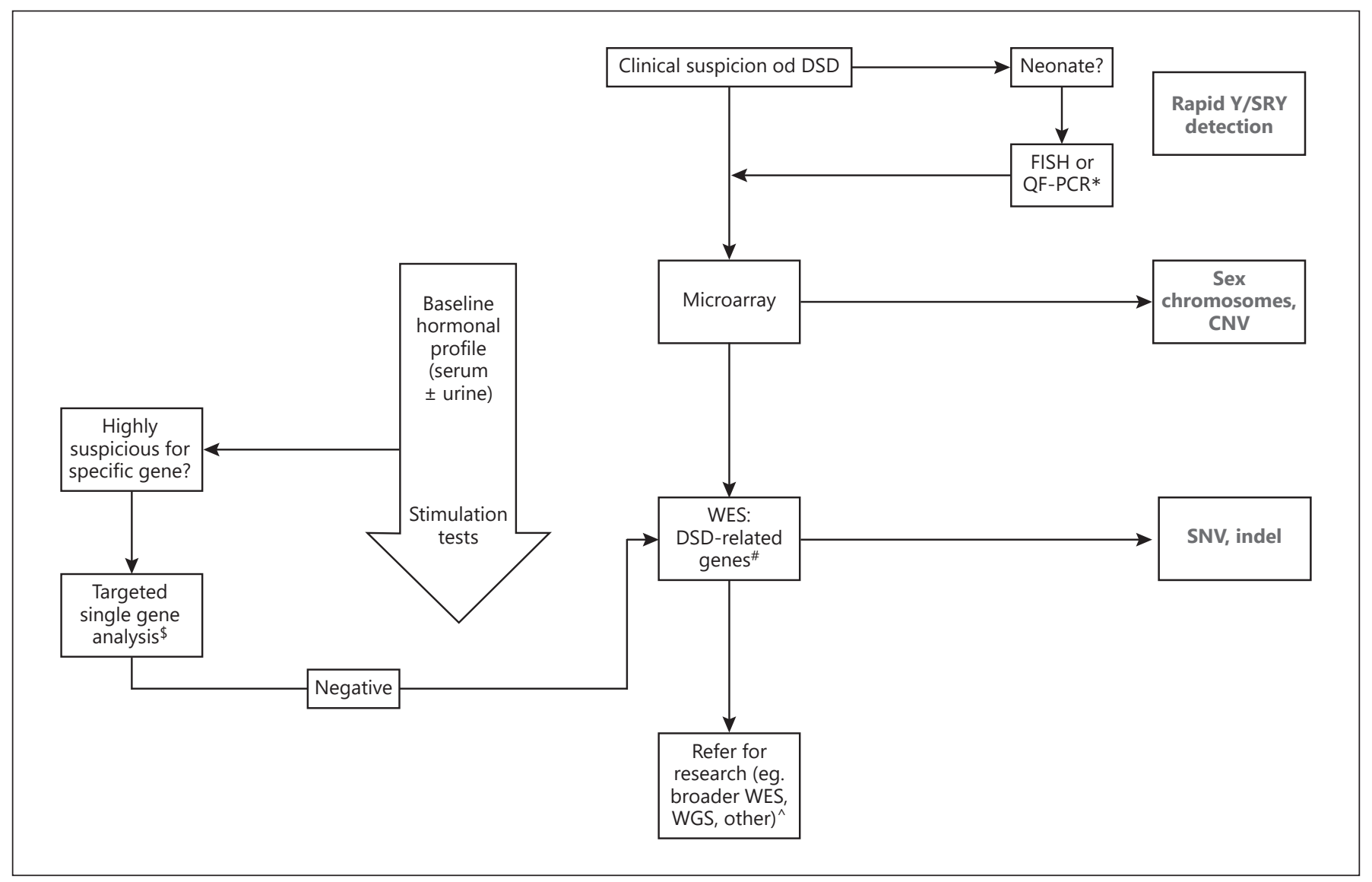

Fig. 1. A recommended approach to genetic testing in a child with DSD. *QF-PCR preferred method. Some centres may only have karyotype available. \#Targeted DSD-panel may be performed if WES is not available. Clinicians should be aware that genes included for analysis differ between laboratories. ${ }^{\$}$ Only recommended in very specific circumstances, e.g., CYP21A2 gene testing or segregation testing in a family. 'See text for more details. Broader WES refers to analysis of genes not currently known to be associ-

Exclusion of non-coding regions is a likely limitation in DSD [113].

\section{Whole-Genome Sequencing}

The future of improved genomic diagnosis in rare disease lies in whole-genome sequencing (WGS), which offers the ability to detect all variations (including SNV and small insertions/deletions - INDELS) in the genome [114]. Currently, WGS is largely used in the research setting; however, clinical-grade WGS is also now available at large referral centres/laboratories. WGS combines SNV, $\mathrm{CNV}$, and structural variant assessment that allows thorough analysis of both coding and non-coding regions and CNV $[15,96]$. It also offers more uniform read depth ated with DSD. CNV, copy number variant; DSD, disorder/differences in sex development; FISH, fluorescence in situ hybridization; indel, insertion/deletion polymorphism; QF-PCR, quantitative fluorescent-polymerase chain reaction; $\mathrm{SNV}$, single-nucleotide variant in gene known to be associated with DSD; SRY, sex-determining region Y; WES, whole-exome sequencing; WGS, wholegenome sequencing.

across the entire genome [97]. Many key DSD genes (such as $S R Y, S O X 9$, and NR5A1) encode transcription factors that require rigorously regulated spatiotemporal expression. This, together with the high rates of DSD without a recognized genomic diagnosis [96], points to non-coding variants in regulatory elements of DSD genes as potentially significant contributors in the genomics of DSD [113], as indeed has been shown to the case for genes such as SOX9 and SOX3 $[92,95]$. In sequencing the whole genome rather than only the protein-coding regions, WGS therefore has the potential to provide a much higher diagnostic yield than WES. Additionally, diagnostic accuracy in the protein-coding regions is also higher with WGS, with lower rates of false-positive SNV (17\% for WGS as 
compared with $78 \%$ for WES [115]). The costs of WGS remain high but will continue to fall and eventually be suitable for more widespread use in a clinical setting. Additional limitations include the enormous complexity of data analysis, particularly in relation to volume of data and limited expertise in interpretation of non-coding variants, and the costs of data storage, but these will likely improve as uptake of WGS increases in the clinical setting.

\section{Suggested Approach to Genomic Testing}

The identification of a pathogenic or likely pathogenic genetic diagnosis can provide certainty about the underlying basis of an individual's condition, enabling correct information for families and individualized clinical management, including monitoring or prophylactic intervention where higher longer term health risks exist. Taken together, the known limitations of traditional diagnostic approaches, alongside increased availability of NGS techniques with improved ability to identify a causative genomic variant, have led to recommendations for the earlier integration of genetic testing alongside hormonal and imaging investigations in the diagnostic pathway $[13,15$, $18,23,96,116]$. Our suggested approach to genomic testing for children with DSD is shown in Figure 1. For neonates with genital variations, where available, QF-PCR offers advantages over FISH for analysis of sex chromosome markers. A microarray will confirm sex chromosome complement, identify sex chromosome aneuploidies and unbalanced rearrangements (but not low level $[<10 \%]$ mosaicism, balanced translocations, or inversions), and offers additional benefits to lower resolution G-band karyotyping as it will identify causative CNV or genomic rearrangements in a significant proportion of children with a DSD. Practically, results of first-tier endocrine testing are typically available in a similar timeframe as a microarray (and in some cases, WES) result. Thereafter, for children without a genetic diagnosis, given the diagnostic and discriminatory limitations of hormonestimulation testing and the high potential for inaccuracy in single gene selection [29], early consideration of NGS is recommended. Selecting the preferred NGS approach will depend on local availability, the complement of genes on a selected panel, gene coverage, and available resources. On the basis of clinical utility and ability to positively impact clinical management and reproductive decisions, the recent American College of Medical Genetics and Genomics (ACMG) clinical practice guideline strongly recommends that ES/GS be considered as a first- or second- tier test for patients with a congenital anomaly diagnosed before the age of 1 year [117]. Since genital variations and other clinical features are often recognized in infancy, this recommendation is relevant to many children with DSD. Targeted WES analysis of DSD-related genes narrows the scope of initial variant curation but affords the option of future re-analysis for children in whom a genomic cause for their DSD is not identified [102]. Clinicians should be aware that capture and analysis techniques vary between commercially available platforms, which are relevant when interpreting a "non-diagnostic" result. Although still not very widely available as a clinical tool, where offered, WGS may alternatively be considered early in the diagnostic pathway, and its use is likely to increase as access to WGS continues to grow [117].

A notable exception to the recommendation to proceed from microarray to NGS techniques is CYP21A2 testing, if desired to confirm a clinical diagnosis of $21 \mathrm{OHD}$ CAH. CYP21A2 is located in the HLA class III region in the major histocompatibility locus on chromosome 6 , a complex genomic region that also contains a highly homologous adjacent pseudogene, CYP21A1P. This necessitates specific single-gene testing protocols that ensure the pseudogene is excluded from analysis; hence, WES is not the test of choice in this scenario.

\section{Challenges and Future Directions}

Challenges in the era of NGS include both the lack of consensus on genes to be included in a targeted analysis of a panel of genes, as well as variant interpretation and classification. In addition, in many instances, despite identification of a SNV in a known gene of interest, there are still insufficient data or strategies to reliably predict the functional consequences for an individual with DSD. Gene panels available in clinical and research settings vary significantly, both in numbers of genes and coverage provided [96]. International best practice for variant classification is based on ACMG guidelines [118] with variants that are deemed pathogenic (class 5), likely pathogenic (class 4), and some VUS (e.g., a novel variant in a gene known to be associated with the disorder, but where there is insufficient current evidence to infer causation for this variant, VUS class $3 \mathrm{a} / 3 \mathrm{~b}$ ) typically reported. However, significant barriers to variant classification as "pathogenic" or "likely pathogenic" exist in DSD, as evidence of causation is lacking for many variants. Identification of VUS often yields important clues for further research; however, functional studies are challenged by the lack of optimal
12

Horm Res Paediatr DOI: $10.1159 / 000520926$
O'Connell/Atlas/Ayers/Sinclair 
models for human DSD. Beyond DNA sequencing, transcriptomic and proteomic analyses can reveal underlying disease mechanisms linked to genetic changes and may be used to understand the functional consequences of a VUS and how it might change gene splicing or isoform expression. However, there are challenges to implementing these techniques in DSD, and their utility in this setting is yet to be shown. This is particularly relevant where the VUS may affect a gene that is expressed in the developing embryonic gonad; hence, relevant tissue for single-cell RNA sequencing or other transcriptomic or proteomic analyses is not readily available and is often lacking in unaffected controls. Nevertheless, alternative methods for functional analyses continue to evolve and have been applied to successfully attribute variant pathogenicity, e.g., use of coculture method to assess $D H H$ gene variant activity [119]. Stem cell technologies where human pluripotent stem cells are differentiated into the tissue of interest may in the future provide a patient-specific means of disease modelling and precision medicine,but are yet to be applied to DSD. Additionally, given the volume of data produced by NGS techniques, there is often a lag to inclusion of published pathogenic variants in publicly available repositories such as ClinVar [91]; hence, additional responsibility falls to the curator and relies on their knowledge of the condition and sufficient time to review the published literature. At a research level, "third-generation" long-read sequencing and optical genome mapping methods are also being employed to overcome some of the challenges posed by the short-read sequencing of WES and WGS, particularly in relation to the detection of large or complex structural variations [91].

NGS techniques have implications for clinical resource requirements and it is recognized that access to such testing is not universally available. Costs and accessibility are likely to continue to improve, but nonetheless may impose a barrier. Although extensive investigation and of- ten-protracted diagnostic odysseys [54] are not uncommon in DSD, barriers to comprehensive utilization of available genetic testing exist, even in DSD reference centres [29]; identifying and diminishing these barriers may prove beneficial in terms of both higher diagnostic yield and shorter time to diagnosis. Future work to both examine cost-effectiveness and improve more widespread availability and appropriate uptake of these techniques for individuals with DSD will also be important. Finally, collaborative research and prospective collection of clinical, biochemical, and molecular data [16] in large collaborative registries (such as iDSD [120] or DSD-Translational Research Network [29]) are recommended. Such efforts will not only optimize our understanding of the interplay between genomics and clinical trajectories in DSD but ultimately afford more accurate assessment of the effects of an accurate diagnosis on health and patientreported outcomes for individuals with DSD.

\section{Conflict of Interest Statement}

The authors have no conflicts of interest to declare.

\section{Funding Sources}

This work was supported by the National Health and Medical Research Council (NHMRC) Research Fellowship 1154187 and Program Grant 546517 (to A.S.).

\section{Author Contributions}

M.A.O. designed the review and wrote the manuscript. G.A. devised the tables and figure and contributed to the manuscript. K.A. and A.S. reviewed and revised earlier versions of the manuscript. All authors have approved the final version.

\section{References}

1 Lee PA, Houk CP, Ahmed SF, Hughes IA; International Consensus Conference on Intersex organized by the Lawson Wilkins Pediatric Endocrine Society and the European Society for Paediatric Endocrinology. Consensus statement on management of intersex disorders. International Consensus Conference on intersex. Pediatrics. 2006;118(2):e488-500.

2 Johnson EK, Rosoklija I, Finlayson C, Chen D, Yerkes EB, Madonna MB, et al. Attitudes towards "disorders of sex development" nomenclature among affected individuals. J Pediatr Urol. 2017;13(6):608. e1-8.
3 Carpenter M. Intersex variations, human rights, and the international classification of diseases. Health Hum Rights. 2018;20(2):205-14.

4 Bennecke E, Köhler B, Röhle R, Thyen U, Gehrmann K, Lee P, et al. Disorders or differences of sex development? Views of affected individuals on DSD terminology. J Sex Res. 2021;58(4):522-31.

5 Berglund A, Johannsen TH, Stochholm K, Aksglaede L, Fedder J, Viuff MH, et al. Incidence, prevalence, diagnostic delay, morbidity, mortality and socioeconomic status in males with 46,XX disorders of sex develop- ment: a Nationwide Study. Hum Reprod. 2017;32(8):1751-60.

6 Bouty A, Ayers KL, Pask A, Heloury Y, Sinclair $\mathrm{AH}$. The genetic and environmental factors underlying hypospadias. Sex Dev. 2015; 9(5):239-59.

7 Knarston I, Ayers K, Sinclair A. Molecular mechanisms associated with 46,XX disorders of sex development. Clin Sci. 2016;130(6):421-32.

8 Nassar N, Bower C, Barker A. Increasing prevalence of hypospadias in Western Australia, 1980-2000. Arch Dis Child. 2007;92(7): 580-4. 
9 Ohnesorg T, Vilain E, Sinclair AH. The genetics of disorders of sex development in humans. Sex Dev. 2014;8(5):262-72.

10 Croft B, Ohnesorg T, Sinclair AH. The role of copy number variants in disorders of sex development. Sex Dev. 2018;12(1-3):19-29.

11 Eggers S, Sinclair A. Mammalian sex determination: insights from humans and mice. Chromosome Res. 2012;20(1):215-38.

12 Ono M, Harley VR. Disorders of sex development: new genes, new concepts. Nat Rev Endocrinol. 2013;9(2):79-91.

13 Audi L, Ahmed SF, Krone N, Cools M, McElreavey $\mathrm{K}$, Holterhus PM, et al. Genetics in endocrinology: approaches to molecular genetic diagnosis in the management of differences/ disorders of sex development (DSD): position paper of EU COST Action BM 1303 "DSDnet”. Eur J Endocrinol. 2018;179(4):R197206.

14 Baetens D, Verdin H, De Baere E, Cools M. Update on the genetics of differences of sex development (DSD). Best Pract Res Clin Endocrinol Metab. 2019;33(3):101271.

15 Croft B, Ayers K, Sinclair A, Ohnesorg T. Review disorders of sex development: the evolving role of genomics in diagnosis and gene discovery. Birth Defects Res C Embryo Today. 2016;108(4):337-50.

16 Cools M, Nordenstrom A, Robeva R, Hall J, Westerveld P, Fluck C, et al. Caring for individuals with a difference of sex development (DSD): a Consensus Statement. Nat Rev Endocrinol. 2018;14(7):415-29.

17 Lee PA, Nordenström A, Houk CP, Ahmed SF, Auchus R, Baratz A, et al. Global disorders of sex development update since 2006: perceptions, approach and care. Horm Res Paediatr. 2016;85(3):158-80.

18 Ahmed SF, Achermann J, Alderson J, Crouch NS, Elford S, Hughes IA, et al. Society for Endocrinology UK Guidance on the initial evaluation of a suspected difference or disorder of sex development (Revised 2021). Clin Endocrinol. 2021;95(6):818-40.

19 Byers HM, Neufeld-Kaiser W, Chang EY, Tsuchiya K, Oehler ES, Adam MP. Discordant sex between fetal screening and postnatal phenotype requires evaluation. J Perinatol. 2019;39(1):28-33.

20 Dhamankar R, DiNonno W, Martin KA Demko ZP, Gomez-Lobo V. Fetal sex results of noninvasive prenatal testing and differences with ultrasonography. Obstet Gynecol. 2020;135(5):1198-206.

21 Smet ME, Scott FP, McLennan AC. Discordant fetal sex on NIPT and ultrasound. Prenat Diagn. 2020;40(11):1353-65.

22 Alimussina M, Diver LA, McGowan R, Ahmed SF. Genetic testing of XY newborns with a suspected disorder of sex development. Curr Opin Pediatr. 2018;30(4):548-57.

23 Wisniewski AB, Batista RL, Costa EMF, Finlayson C, Sircili MHP, Dénes FT, et al. Management of 46,XY differences/disorders of sex development (DSD) throughout life. Endocr Rev. 2019;40(6):1547-72.
24 Baronio F, Ortolano R, Menabò S, Cassio A, Baldazzi L, Di Natale V, et al. 46,XX DSD due to androgen excess in monogenic disorders of steroidogenesis: genetic, biochemical, and clinical features. Int J Mol Sci. 2019;20(18): 4605.

25 Grinspon RP, Rey RA. Disorders of sex development with testicular differentiation in SRY-negative 46,XX individuals: clinical and genetic aspects. Sex Dev. 2016;10(1):1-11.

26 Sinclair AH, Berta P, Palmer MS, Hawkins JR, Griffiths BL, Smith MJ, et al. A gene from the human sex-determining region encodes a protein with homology to a conserved DNAbinding motif. Nature. 1990;346(6281):2404.

27 Koopman P, Gubbay J, Vivian N, Goodfellow P, Lovell-Badge R. Male development of chromosomally female mice transgenic for Sry. Nature. 1991;351(6322):117-21.

28 Berta P, Hawkins JR, Sinclair AH, Taylor A, Griffiths BL, Goodfellow PN, et al. Genetic evidence equating SRY and the testis-determining factor. Nature. 1990;348(6300):44850.

29 Delot EC, Papp JC, Workgroup D-TG, Sandberg DE, Vilain E. Genetics of disorders of sex development: the DSD-TRN experience. Endocrinol Metab Clin North Am. 2017;46(2): 519-37.

30 Eggers S, Sadedin S, van den Bergen JA, Robevska G, Ohnesorg T, Hewitt J, et al. Disorders of sex development: insights from targeted gene sequencing of a large international patient cohort. Genome Biol. 2016;17(1): 243.

31 Baxter RM, Arboleda VA, Lee H, Barseghyan $\mathrm{H}$, Adam MP, Fechner PY, et al. Exome sequencing for the diagnosis of $46, \mathrm{XY}$ disorders of sex development. J Clin Endocrinol Metab. 2015;100(2):E333-44.

32 Buonocore F, Clifford-Mobley O, King TFJ, Striglioni N, Man E, Suntharalingham JP, et al. Next-generation sequencing reveals novel genetic variants (SRY, DMRT1, NR5A1, DHH, DHX37) in adults with 46,XY DSD. J Endocr Soc. 2019;3(12):2341-60.

33 Camats N, Pandey AV, Fernandez-Cancio M, Andaluz P, Janner M, Toran N, et al. Ten novel mutations in the NR5A1 gene cause disordered sex development in 46,XY and ovarian insufficiency in 46,XX individuals. J Clin Endocrinol Metab. 2012;97(7):E1294-306.

34 Domenice S, Machado AZ, Ferreira FM, Ferraz-de-Souza B, Lerario AM, Lin L, et al. Wide spectrum of NR5A1-related phenotypes in 46,XY and 46,XX individuals. Birth Defects Res C Embryo Today. 2016;108(4):309-20.

35 Bashamboo A, Donohoue PA, Vilain E, Rojo S, Calvel P, Seneviratne SN, et al. A recurrent p.Arg92Trp variant in steroidogenic factor-1 (NR5A1) can act as a molecular switch in human sex development. Hum Mol Genet. 2016; 25(23):5286.

36 Sadovsky Y, Crawford PA, Woodson KG, Polish JA, Clements MA, Tourtellotte LM, et al. Mice deficient in the orphan receptor ste- roidogenic factor 1 lack adrenal glands and gonads but express P450 side-chain-cleavage enzyme in the placenta and have normal embryonic serum levels of corticosteroids. Proc Natl Acad Sci U S A. 1995;92(24): 10939-43.

37 Achermann JC, Ito M, Ito M, Hindmarsh PC, Jameson JL. A mutation in the gene encoding steroidogenic factor- 1 causes XY sex reversal and adrenal failure in humans. Nat Genet. 1999;22(2):125-6.

38 Lourenco D, Brauner R, Lin L, De Perdigo A, Weryha G, Muresan M, et al. Mutations in NR5A1 associated with ovarian insufficiency. N Engl J Med. 2009;360(12):1200-10.

39 Baetens D, Stoop H, Peelman F, Todeschini AL, Rosseel T, Coppieters F, et al. NR5A1 is a novel disease gene for 46,XX testicular and ovotesticular disorders of sex development. Genet Med. 2017;19(4):367-76.

40 Miyado M, Inui M, Igarashi M, Katoh-Fukui Y, Takasawa K, Hakoda A, et al. The p.R92W variant of NR5A1/Nr5al induces testicular development of 46,XX gonads in humans, but not in mice: phenotypic comparison of human patients and mutation-induced mice. Biol Sex Differ. 2016;7:56.

41 Mazen I, Abdel-Hamid M, Mekkawy M, Bignon-Topalovic J, Boudjenah R, El Gammal $\mathrm{M}$, et al. Identification of NR5A1 mutations and possible digenic inheritance in 46 , XY gonadal dysgenesis. Sex Dev. 2016;10(3):14751.

42 Camats N, Fernández-Cancio $\mathrm{M}$, Audí L, Schaller A, Flück CE. Broad phenotypes in heterozygous NR5A1 46,XY patients with a disorder of sex development: an oligogenic origin?. Eur J Hum Genet. 2018;26(9):132938.

43 Ahmed SF, Achermann JC, Arlt W, Balen A, Conway G, Edwards Z, et al. Society for Endocrinology UK guidance on the initial evaluation of an infant or an adolescent with a suspected disorder of sex development (Revised 2015). Clin Endocrinol. 2016;84(5): 771-88.

44 Hutson JM, Grover SR, O’Connell M, Pennell SD. Malformation syndromes associated with disorders of sex development. Nat Rev Endocrinol. 2014;10(8):476-87.

45 León NY, Reyes AP, Harley VR. A clinical algorithm to diagnose differences of sex development. Lancet Diabetes Endocrinol. 2019; 7(7):560-74.

46 Cox K, Bryce J, Jiang J, Rodie M, Sinnott R, Alkhawari $M$, et al. Novel associations in disorders of sex development: findings from the I-DSD Registry. J Clin Endocrinol Metab. 2014;99(2):E348-55

47 Ahmed SF, Khwaja O, Hughes IA. The role of a clinical score in the assessment of ambiguous genitalia. BJU Int. 2000;85(1):120-4.

48 van der Straaten S, Springer A, Zecic A, Hebenstreit D, Tonnhofer U, Gawlik A, et al. The external genitalia score (EGS): a European Multicenter Validation Study. J Clin Endocrinol Metab. 2020;105(3). 
49 Prader A. [Genital findings in the female pseudo-hermaphroditism of the congenital adrenogenital syndrome; morphology, frequency, development and heredity of the different genital forms]. Helv Paediatr Acta. 1954;9(3):231-48.

50 Rey RA, Grinspon RP. Normal male sexual differentiation and aetiology of disorders of sex development. Best Pract Res Clin Endocrinol Metab. 2011;25(2):221-38.

51 Feldman KW, Smith DW. Fetal phallic growth and penile standards for newborn male infants. J Pediatr. 1975;86(3):395-8.

52 Kulle A, Krone N, Holterhus PM, Schuler G, Greaves RF, Juul A, et al. Steroid hormone analysis in diagnosis and treatment of DSD: position paper of EU COST Action BM 1303 "DSDnet”. Eur J Endocrinol. 2017;176(5):P1-9.

53 Krone N, Arlt W. Genetics of congenital adrenal hyperplasia. Best Pract Res Clin Endocrinol Metab. 2009;23(2):181-92.

54 van Zoest M, Bijker EM, Kortmann BBM, Kempers M, van Herwaarden AE, van der Velden J, et al. Sex assignment and diagnostics in infants with ambiguous genitalia: a Single-Center Retrospective Study. Sex Dev. 2019;13(3):109-17.

55 Nixon R, Cerqueira V, Kyriakou A, LucasHerald A, McNeilly J, McMillan M, et al. Prevalence of endocrine and genetic abnormalities in boys evaluated systematically for a disorder of sex development. Hum Reprod. 2017;32(10):2130-7.

56 Hiort O, Birnbaum W, Marshall L, Wunsch L, Werner R, Schroder T, et al. Management of disorders of sex development. Nat Rev Endocrinol. 2014;10(9):520-9.

57 Tomlinson C, Macintyre H, Dorrian CA, Ahmed SF, Wallace AM. Testosterone measurements in early infancy. Arch Dis Child Fetal Neonatal Ed. 2004;89(6):F558-9.

58 Bertelloni S, Russo G, Baroncelli GI. Human chorionic gonadotropin test: old uncertainties, new perspectives, and value in $46, \mathrm{XY}$ disorders of sex development. Sex Dev. 2018; 12(1-3):41-9.

59 Maimoun L, Philibert P, Cammas B, Audran F, Bouchard P, Fenichel P, et al. Phenotypical, biological, and molecular heterogeneity of 5alpha-reductase deficiency: an extensive international experience of 55 patients. J Clin Endocrinol Metab. 2011;96(2):296-307.

60 Khattab A, Yuen T, Yau M, Domenice S, Frade Costa EM, Diya K, et al. Pitfalls in hormonal diagnosis of 17-beta hydroxysteroid dehydrogenase III deficiency. J Pediatr Endocrinol Metab. 2015;28(5-6):623-8.

61 Lucas-Herald AK, Rodie M, Lucaccioni L, Shapiro D, McNeilly J, Shaikh MG, et al. The pitfalls associated with urinary steroid metabolite ratios in children undergoing investigations for suspected disorders of steroid synthesis. Int J Pediatr Endocrinol. 2015;2015(1):10.

62 Guerra-Junior G, Andrade KC, Barcelos IHK, Maciel-Guerra AT. Imaging techniques in the diagnostic journey of disorders of sex development. Sex Dev. 2018;12(1-3):95-9.
63 Lee PA, Nordenstrom A, Houk CP, Ahmed SF, Auchus R, Baratz A, et al. Global disorders of sex development update since 2006: perceptions, approach and care. Horm Res Paediatr. 2016;85(3):158-80.

64 Furtado PS, Moraes F, Lago R, Barros LO, Toralles MB, Barroso U Jr. Gender dysphoria associated with disorders of sex development. Nat Rev Urol. 2012;9(11):620-7.

65 Kreukels BPC, Köhler B, Nordenström A, Roehle R, Thyen U, Bouvattier C, et al. Gender dysphoria and gender change in disorders of sex development/intersex conditions: results from the DSD-LIFE Study. J Sex Med. 2018;15(5):777-85.

66 Mendonca BB, Gomes NL, Costa EM, Inacio M, Martin RM, Nishi MY, et al. 46,XY disorder of sex development (DSD) due to 17betahydroxysteroid dehydrogenase type 3 deficiency. J Steroid Biochem Mol Biol. 2017; 165(Pt A):79-85.

67 Cohen-Kettenis PT. Gender change in 46,XY persons with 5alpha-reductase-2 deficiency and 17beta-hydroxysteroid dehydrogenase-3 deficiency. Arch Sex Behav. 2005;34(4):399410.

68 Khorashad BS, Aghili Z, Kreukels BP, Hiradfar M, Roshan GM, Afkhamizadeh M, et al. Psychosexual outcome among iranian individuals with 5alpha-reductase deficiency type 2 and its relationship with parental sexism. J Sex Med. 2016;13(11):1629-41.

69 Costa EM, Domenice S, Sircili MH, Inacio M, Mendonca BB. DSD due to $5 a$-reductase 2 deficiency: from diagnosis to long term outcome. Semin Reprod Med. 2012;30(5):42731.

70 Gangaher A, Chauhan V, Jyotsna VP, Mehta $M$. Gender identity and gender of rearing in $46 \mathrm{XY}$ disorders of sexual development. Indian J Endocrinol Metab. 2016;20(4):536-41.

71 Finlayson C, Fritsch MK, Johnson EK, Rosoklija I, Gosiengfiao Y, Yerkes E, et al. Presence of germ cells in disorders of sex development: implications for fertility potential and preservation. J Urol. 2017;197(3 Pt 2):937-43.

72 Slowikowska-Hilczer J, Hirschberg AL, Claahsen-van der Grinten H, Reisch N, Bouvattier $\mathrm{C}$, Thyen $\mathrm{U}$, et al. Fertility outcome and information on fertility issues in individuals with different forms of disorders of sex development: findings from the dsd-LIFE study. Fertil Steril. 2017;108(5):822-31.

73 Achermann JC, Domenice S, Bachega TA, Nishi MY, Mendonca BB. Disorders of sex development: effect of molecular diagnostics. Nat Rev Endocrinol. 2015;11(8):478-88.

74 Hersmus R, van Bever Y, Wolffenbuttel KP, Biermann K, Cools M, Looijenga LH. The biology of germ cell tumors in disorders of sex development. Clin Genet. 2017;91(2):292301.

75 van der Zwan YG, Biermann K, Wolffenbuttel KP, Cools M, Looijenga LH. Gonadal maldevelopment as risk factor for germ cell cancer: towards a clinical decision model. Eur Urol. 2015;67(4):692-701.
76 Cools M, Looijenga L. Update on the pathophysiology and risk factors for the development of malignant testicular germ cell tumors in complete androgen insensitivity syndrome. Sex Dev. 2017;11(4):175-81.

77 Cools M, Drop SL, Wolffenbuttel KP, Oosterhuis JW, Looijenga LH. Germ cell tumors in the intersex gonad: old paths, new directions, moving frontiers. Endocr Rev. 2006;27(5): $468-84$

78 Wolffenbuttel KP, Hersmus R, Stoop H, Biermann K, Hoebeke P, Cools M, et al. Gonadal dysgenesis in disorders of sex development: diagnosis and surgical management. J Pediatr Urol. 2016;12(6):411-6.

79 Weidler EM, Linnaus ME, Baratz AB, Goncalves LF, Bailey S, Hernandez SJ, et al. A management protocol for gonad preservation in patients with androgen insensitivity syndrome. J Pediatr Adolesc Gynecol. 2019; 32(6):605-11.

80 Vora KA, Hanna CA, Neville KA, Bergman PB, Grover SR, O'Connell MA, et al. Role of crosscampus multidisciplinary team meetings in decision-making for children and adolescents with differences of sex development/intersex. J Paediatr Child Health. 2021;57(9):1402-7.

81 Symon A, Harley V. SOX9: a genomic view of tissue specific expression and action. Int $\mathrm{J}$ Biochem Cell Biol. 2017;87:18-22.

82 Lourenco D, Brauner R, Rybczynska M, Nihoul-Fekete C, McElreavey K, Bashamboo A. Loss-of-function mutation in GATA4 causes anomalies of human testicular development. Proc Natl Acad Sci U S A. 2011;108(4):1597602.

83 Werner R, Merz H, Birnbaum W, Marshall L, Schroder T, Reiz B, et al. 46,XY gonadal dysgenesis due to a homozygous mutation in desert hedgehog (DHH) identified by exome sequencing. J Clin Endocrinol Metab. 2015; 100(7):E1022-9.

84 Umehara F, Tate G, Itoh K, Yamaguchi N, Douchi T, Mitsuya T, et al. A novel mutation of desert hedgehog in a patient with $46, \mathrm{XY}$ partial gonadal dysgenesis accompanied by minifascicular neuropathy. Am J Hum Genet. 2000;67(5):1302-5.

85 Lipska BS, Ranchin B, Iatropoulos P, Gellermann J, Melk A, Ozaltin F, et al. Genotypephenotype associations in WT1 glomerulopathy. Kidney Int. 2014;85(5):1169-78.

86 Byers HM, Fossum M, Wu HY. How geneticists think about differences/disorders of sexual development (DSD): a conversation. J Pediatr Urol. 2020;16(6):760-7.

87 Alhomaidah D, McGowan R, Ahmed SF. The current state of diagnostic genetics for conditions affecting sex development. Clin Genet. 2017;91(2):157-62.

88 Ledig S, Hiort O, Scherer G, Hoffmann M, Wolff G, Morlot S, et al. Array-CGH analysis in patients with syndromic and non-syndromic XY gonadal dysgenesis: evaluation of array CGH as diagnostic tool and search for new candidate loci. Hum Reprod. 2010; 25(10):2637-46. 
89 Tannour-Louet M, Han S, Corbett ST, Louet JF, Yatsenko S, Meyers L, et al. Identification of de novo copy number variants associated with human disorders of sexual development. PLoS One. 2010;5(10):e15392.

90 Miller DT, Adam MP, Aradhya S, Biesecker LG, Brothman AR, Carter NP, et al. Consensus statement: chromosomal microarray is a first-tier clinical diagnostic test for individuals with developmental disabilities or congenital anomalies. Am J Hum Genet. 2010;86(5): 749-64.

91 Parivesh A, Barseghyan H, Délot E, Vilain E. Translating genomics to the clinical diagnosis of disorders/differences of sex development. Curr Top Dev Biol. 2019;134:317-75.

92 Croft B, Ohnesorg T, Hewitt J, Bowles J, Quinn A, Tan J, et al. Human sex reversal is caused by duplication or deletion of core enhancers upstream of SOX9. Nat Commun. 2018;9(1):5319.

93 White S, Ohnesorg T, Notini A, Roeszler K, Hewitt J, Daggag $\mathrm{H}$, et al. Copy number variation in patients with disorders of sex development due to $46, \mathrm{XY}$ gonadal dysgenesis. PLoS One. 2011;6(3):e17793.

94 Norling A, Lindén Hirschberg A, Iwarsson E, Persson B, Wedell A, Barbaro M. Novel candidate genes for 46,XY gonadal dysgenesis identified by a customized $1 \mathrm{~m}$ array-CGH platform. Eur J Med Genet. 2013;56(12):6618.

95 Sutton E, Hughes J, White S, Sekido R, Tan J, Arboleda V, et al. Identification of SOX3 as an $\mathrm{XX}$ male sex reversal gene in mice and humans. J Clin Invest. 2011;121(1):328-41.

96 Barseghyan H, Délot EC, Vilain E. New technologies to uncover the molecular basis of disorders of sex development. Mol Cell Endocrinol. 2018;468:60-9.

97 Bashamboo A, Ledig S, Wieacker P, Achermann JC, Achermann J, McElreavey K. New technologies for the identification of novel genetic markers of disorders of sex development (DSD). Sex Dev. 2010;4(4-5):213-24.

98 Dong Y, Yi Y, Yao H, Yang Z, Hu H, Liu J, et al. Targeted next-generation sequencing identification of mutations in patients with disorders of sex development. BMC Med Genet. 2016;17:23.

99 Ozen S, Onay H, Atik T, Solmaz AE, Ozkinay F, Goksen D, et al. Rapid molecular genetic diagnosis with next-generation sequencing in 46, XY disorders of sex development cases: efficiency and cost assessment. Horm Res Paediatr. 2017;87(2):81-7.
100 Kim JH, Kang E, Heo SH, Kim GH, Jang JH, Cho EH, et al. Diagnostic yield of targeted gene panel sequencing to identify the genetic etiology of disorders of sex development. Mol Cell Endocrinol. 2017;444:19-25.

101 Fan Y, Zhang X, Wang L, Wang R, Huang Z, Sun Y, et al. Diagnostic application of targeted next-generation sequencing of 80 genes associated with disorders of sexual development. Sci Rep. 2017;7:44536.

102 Wenger AM, Guturu H, Bernstein JA, Bejerano G. Systematic reanalysis of clinical exome data yields additional diagnoses: implications for providers. Genet Med. 2017;19(2):209-14.

103 Lee H, Deignan JL, Dorrani N, Strom SP, Kantarci S, Quintero-Rivera F, et al. Clinical exome sequencing for genetic identification of rare Mendelian disorders. JAMA. 2014; 312(18):1880-7.

104 Tan TY, Lunke S, Chong B, Phelan D, Fanjul-Fernandez M, Marum JE, et al. A headto-head evaluation of the diagnostic efficacy and costs of trio versus singleton exome sequencing analysis. Eur J Hum Genet. 2019; 27(12):1791-9.

105 Portnoi MF, Dumargne MC, Rojo S, Witchel SF, Duncan AJ, Eozenou C, et al. Mutations involving the SRY-related gene SOX8 are associated with a spectrum of human reproductive anomalies. Hum Mol Genet. 2018;27(7):1228-40.

106 Harris A, Siggers P, Corrochano S, Warr N, Sagar D, Grimes DT, et al. ZNRF3 functions in mammalian sex determination by inhibiting canonical WNT signaling. Proc Natl Acad Sci U S A. 2018;115(21):5474-9.

107 McElreavey K, Jorgensen A, Eozenou C, Merel T, Bignon-Topalovic J, Tan DS, et al. Pathogenic variants in the DEAH-box RNA helicase DHX37 are a frequent cause of 46,XY gonadal dysgenesis and 46,XY testicular regression syndrome. Genet Med. 2020;22(1):150-9.

108 Ayers K, Kumar R, Robevska G, Bruell S, Bell K, Malik MA, et al. Familial bilateral cryptorchidism is caused by recessive variants in RXFP2. J Med Genet. 2019;56(11):727-33.

109 Tucker EJ, Rius R, Jaillard S, Bell K, Lamont PJ, Travessa A, et al. Genomic sequencing highlights the diverse molecular causes of Perrault syndrome: a peroxisomal disorder (PEX6), metabolic disorders (CLPP, GGPS1), and mtDNA maintenance/translation disorders (LARS2, TFAM). Hum Genet. $2020 ; 139(10): 1325-43$.

110 Jaillard S, Sreenivasan R, Beaumont M, Robevska G, Dubourg C, Knarston IM, et al. Analysis of NR5A1 in 142 patients with premature ovarian insufficiency, diminished ovarian reserve, or unexplained infertility. Maturitas. 2020;131:78-86.
111 Jaillard S, Bell K, Akloul L, Walton K, McElreavy K, Stocker WA, et al. New insights into the genetic basis of premature ovarian insufficiency: novel causative variants and candidate genes revealed by genomic sequencing. Maturitas. 2020;141:9-19.

112 Koboldt DC. Best practices for variant calling in clinical sequencing. Genome Med. 2020;12(1):91.

113 Baetens D, Mendonça BB, Verdin H, Cools $\mathrm{M}$, De Baere E. Non-coding variation in disorders of sex development. Clin Genet. 2017; 91(2):163-72.

114 Wright CF, FitzPatrick DR, Firth HV. Paediatric genomics: diagnosing rare disease in children. Nat Rev Genet. 2018;19(5):325.

115 Belkadi A, Bolze A, Itan Y, Cobat A, Vincent $\mathrm{QB}$, Antipenko A, et al. Whole-genome sequencing is more powerful than wholeexome sequencing for detecting exome variants. Proc Natl Acad Sci U S A. 2015;112(17): 5473-8.

116 Alhomaidah D, McGowan R, Ahmed SF. The current state of diagnostic genetics for conditions affecting sex development. Clin Genet. 2017;91(2):157-62.

117 Manickam K, McClain MR, Demmer LA, Biswas S, Kearney HM, Malinowski J, et al. Exome and genome sequencing for pediatric patients with congenital anomalies or intellectual disability: an evidence-based clinical guideline of the American College of Medical Genetics and Genomics (ACMG). Genet Med. 2021;23(11):2029-37.

118 Richards S, Aziz N, Bale S, Bick D, Das S, Gastier-Foster J, et al. Standards and guidelines for the interpretation of sequence variants: a joint consensus recommendation of the American College of Medical Genetics and Genomics and the Association for Molecular Pathology. Genet Med. 2015;17(5): 405-24.

119 Ayers K, van den Bergen J, Robevska G, Listyasari N, Raza J, Atta I, et al. Functional analysis of novel desert hedgehog gene variants improves the clinical interpretation of genomic data and provides a more accurate diagnosis for patients with 46,XY differences of sex development. J Med Genet. 2019; 56(7):434-43.

120 Ahmed SF, Bryce J, Hiort O. International networks for supporting research and clini$\mathrm{cal}$ care in the field of disorders of sex development. Endocr Dev. 2014;27:284-92. 